\title{
Sobre fronteiras e permeamentos
}

\author{
Eduardo Ferraz Felippe
}

LaCapra, Dominick. History, Literature, Critical Theory. Ithaca, Nova York: Cornell University Press, 2013.

Mais conhecida por aqueles que lidam com discussóes que tangenciam história, filosofia e literatura, a obra de Dominick LaCapra ainda náo obteve uma traduçáo de fôlego no Brasil. Por mais que entendamos essa lacuna como uma entre muitas, o agora professor emérito da universidade de Cornell propóe uma obra que impóe problemas destacáveis para a historiografia e alça sua reflexão a uma das mais necessárias do cenário universitário contemporâneo. Pode-se conceber que as variaçóes propostas em seus diversos livros, desde as abordagens voltadas à história intelectual, do início da década de oitenta do século passado, até aquelas direcionadas à análise de alguns ficcionistas contemporâneos, tenham sido variações de um problema central da historiografia: os limites e possibilidades da história intelectual. Seus livros dialogam entre si ao mesmo tempo que apresentam uma distinçáo sensível entre eles; girando sobre seus próprios passos, LaCapra permanece em diálogo com um temário vivo desde os primeiros livros, enquanto joga luzes a um novo horizonte de sentido.

Em tempos de predominância do estruturalismo, LaCapra começou sua carreira acadêmica ao interrogar-se acerca da tese hegemônica da submissáo do intelectual ao edifício da história. Nesse instante, percebeu a necessidade de reforma e deslocamento da história intelectual de seu lugar de sinopse de ideias e sistemas de grandes pensadores ou da autoconsideração enquanto história da filosofia. LaCapra dialoga com o cânon ocidental, discutindo e ampliando-o, por meio da crítica aguda a autores contemporâneos seus, como Derrida e Foucault, até autores que o marcaram, como Marx e Benjamin. Inicialmente aposta em uma perspectiva interdisciplinar, de modo que seu ataque às teorias totalizantes não implicou o embarque em propostas pós-modernas pouco atentas à historicidade do texto. Já em Soundings in Critical Theory (1989) o marxismo, a psicanálise e o pós-estruturalismo são articulados à historiografia em sua dimensão crítica e autocrítica. Desse modo, o caminho da história intelectual, em sua diferenciaçáo frente à história social, se bifurca com o caminho da historiografia, sendo a dupla face de uma mesma proposta intelectual sustentada pelo professor de Cornell. sino médio e da Universidade do Estado do Rio de Janeiro (UERJ). Rio de Janeiro, RJ, Brasil. E-mail: eferrazfelippe@oi.com.br. 
A interdisciplinaridade do início da carreira pode ser detectada nas suas consideraçôes sobre os limites da noção de contexto que impóe a autores como Flaubert e Baudelaire. Essa questáo será alvo de uma avaliação específica de Hayden White em "The context in the text: Method and Ideology in Intellectual History" em seu The Content of Form: Narrative Discourse and Historical Representation (1990) em que dialoga com a obra prévia do autor de History, Literature, Critical Theory. O problema do contexto já está presente no início na tese de livre-docência de LaCapra, ao ponderar que Durkheim náo deve ser compreendido somente como uma metodologia de pesquisa, mas um texto a ser lido e articulado dentro do contexto. A partir dele, critica algumas análises que o submetem a esse contexto pela utilização de argumentos firmes, postos em contradição com algumas consideraçôes do próprio Durkheim. Essa perspectiva de um ataque ao "historicismo" na leitura dos textos enfatiza sua perspectiva dialógica de relacionamento com o passado. Náo se trata de recusar completamente os protocolos de análise, e sim complementá-los e superá-los.

Longe está LaCapra de um subjetivismo relativista que apresenta os textos como desligados do contexto. Afirma, de modo incisivo, em seu History and Criticism (1985), manter uma distância preventiva do chamado "fetichismo de arquivo" (p. 92). A questão central para LaCapra é a recusa explícita de um empirismo radical, utilizado muitas das vezes como "recusa a se ler os textos", como pondera em Rethinking Intellectual History (1983) (p. 14). A noção de leitura como interpretação é central em toda a sua trajetória intelectual, especialmente aquela enfatizada na década de 1980 . O historiador deve evitar uma acumulação neopositivista de informação com o fito de empreender leituras novas que não se resumam a descobrir novas fontes.

Esse percurso levou Dominick LaCapra a entrar em contato com as propostas do "linguistic turn"; contudo, não se deve afirmar, pelo menos de modo tâo imediato, que LaCapra deve ser considerado um "historiador derrideano". Creio que LaCapra não concordaria plenamente com a noção de que não há nada fora do texto; pelo contrário, há uma leitura apropriativa e altamente seletiva voltada a criticar oposiçóes binárias sustentadas por opçóes historiográficas pouco atentas ao texto. Transcender a análise binária não implica o desconhecimento da sua importância em processos históricos ou no presente, em outro viés, considera que periodização histórica é um tema destacável ao historiador. A desconstrução é incorporada, mas não adotada de forma plena; Derrida e Heidegger estáo entre outros autores, como Marx, Freud e Bakhtin, que, por fim, valorizam a intertextualidade como procedimento de escrita, tendo como centro a dimensão retórica dos textos. A estratégia da história intelectual combina investigação empírica com vozes do presente e do passado, que incluem o autor e suas fontes em uma temporalidade marcada por deslocamentos, continuidades e rupturas.

Já em seu History, Literature, Critical Theory (2013), Dominick LaCapra continua sua exploração acerca das relaçóes comple- 
xas entre história e literatura, entendendo a história como processo e representação. Trata-se, como sempre fez questão de deixar claro, da incorporação atenciosa da obra de Hayden White, especialmente de seu livro mais famoso, Metahistória (1973). Em termos gerais, seu livro se divide entre um ensaio inicial, três capítulos de análise específica de alguns autores contemporâneos, como W. G. Sebald e J. M. Coetzee, e termina com um epílogo acerca da questão da violência em Slavoj Žižek. Um motivo recorrente do livro é a questão do sagrado, a relação problemática estabelecida com o sacrifício e sua virulenta manifestação como violência política e social.

O foco da discussão acerca da história está na questão da violência, com atenção particular a tema que já se dedicou anteriormente: a "solução final". Em termos gerais, o autor está atento ao contato entre o sublime, o sagrado, o "pós-secular" e a questão da redenção absoluta, assim como as possíveis implicaçóes da procura pela violência e, por vezes, sacrificial ou as práticas quase-sacrificiais envolvendo transgressão radical, vitimização e a expiação (p. 1). Por diversas vezes, LaCapra deriva o argumento para a reflexão acerca do que chama de "pós-secular”, a época atual. O termo provém de sua leitura de Hans Blumenberg, especialmente de duas obras, The Legitimacy of modern age (1986) e Work on Mith (1985). LaCapra destaca que, para Hans Blumenberg, a descontinuidade entre o mundo pré-moderno e o mundo moderno fundamenta o termo "legitimidade da época moderna". Esse argumento torna-se mais claro quando propóe a aproximação entre Blumenberg e Jürgen Habermas em seu "Notes on a Postsecular society" (2008), por meio de uma abordagem que valoriza a tradição filosófica e a sociologia.

Em seu livro mais recente, é a questão do trauma e do genocídio nazi o disparador da escrita e dos paradoxos nela enredados. A leitura feita de Coetzee e Sebald, as soluçôes narrativas levantadas por Jonathan Littell, o fechamento da proposta com Slavoj Žižek, a conexão com a violência, tem no tópico do trauma o porto onde se ancoram afirmativas e de onde partem novos rumos. Está posta, de modo inexorável, a questão da narrativa em nossa lida com o passado. "A abordagem do trauma, mormente sua expressão narrativa, tem sido acompanhada por um paradoxo ou um duplo enlace: o indizível ainda clama por um discurso sem fim" (p. 33). Por vezes um processo de intensificação, por outras um ato de abrandamento, as semelhanças e diferenças entre os testemunhos e todas as tentativas de "representar as experiências traumáticas e eventos" são determinadas por meio da forma com que esse paradoxo é negociado na narrativa.

O temário do trauma ganhou tessitura consistente em seus argumentos ao longo das décadas de 1990 e 2000. A empreitada mais significativa nessa direção foi Writing History, Writing Trauma (2001). A adaptação de conceitos psicanalíticos para a análise histórica está associada ao emprego da crítica sociocultural e política para elucidar o trauma e seus efeitos na cultura. Writing History, Writing Trauma (2001) também marca a tentativa explícita de LaCapra de se 
diferenciar de Hayden White, por mais que concorde em muitos aspectos, especialmente os dedicados à narração. Atento à leitura que White faz de Roland Barthes, LaCapra enfatiza o vínculo entre o autor de Metahistória e o livro Escrever, verbo intransitivo, especialmente no debate levantado quando da publicaçáo do livro Probing the Limits of Representation: Nazism and the "Final Solution" (1992), de Saul Friedländer.

Especialmente J. M. Coetzee (Elisabeth Costello e Desonra) e W. G. Sebald (Anéis de Saturno) são os ficcionistas atrelados às principais consideraçóes de LaCapra. Além da semelhança por pseudônimos, a escolha por emigrarem de suas terras natais, e a atenção dada pelo primeiro ao segundo, destaca-se a sofisticaçáo da questáo da linguagem e a combinação entre análise crítica de outros autores (especialmente de Kafka e Flaubert) com uma autorreflexão profunda ou um "diálogo interno", nos termos de Mikhail Bakhtin. LaCapra percebe que o Holocausto representa para Sebald aquilo que o apartheid e o colonialismo significam para Coetzee: a questáo do mal e o abusivo tratamento de humanos e não humanos. A presença da pesquisa de arquivo, notória em W. G. Sebald, mas também presente em J. M. Coetzee, e a questáo da memória estão coligadas ao problema do realismo, especialmente do traumático realismo, em relação à técnica formal de ambos.

O tema do trauma, enquanto modalidade do sublime, permite a LaCapra outros voos associados aos limites e às possibilidades da narrativa. Na verdade, um deslocamento. Passa a estar em jogo o tema da dimensão ética do historiador. Para tanto, a entrada em cena do romance de Jonathan Littell e as questôes postas por Saul Friedländer auxiliam no entendimento da questão. Especialmente atento às preocupaçôes do autor de As Benevolentes (2006), de modo destacado por sua atenção ao discurso dos agressores, LaCapra considera que "entender os agressores é importante epistemologicamente, eticamente e politicamente". Antes, lembra-nos do valor do reconhecimento empático ao inveterar em acontecimentos extremos. Há um duplo caminho sendo percorrido por veredas nem sempre coincidentes ao longo do livro: por um lado, admitir a nossa própria possibilidade de envolvimento no crime, posto que nenhum de nós está plenamente cônscio em suas respostas e, por outro lado, propiciar nossa autocompreensão por meio da tentativa de imputar sentido a Max Aue, personagem principal, como um homem qualquer.

Littell discorda de que seu romance deveria ser chamado de um novo Guerra e $p a z$. A leitura que fez de Maurice Blanchot e Georges Bataille, duas de suas preferências, fundamenta a "zona cinzenta" da escrita na qual todo escritor repousa - o espaço literário que necessita para criar e lapidar o seu Max Aue. A natureza da relação entre agressor e vítima em As benevolentes é confusa e marcada pela ambiguidade do personagem central. O que constitui a "verdade romanesca" para Littell permanece em sombras, mas há a busca por ir além de uma "verdade histórica" sem necessariamente transcendê-la ou falsificá-la. "As benevolentes transcendem a verdade histórica (...) em sua tentativa 
de amalgamar ou reverter a relação entre agressor e vítima” (p. 116).

O último capítulo e o epílogo deslocam a atenção para a obra de Slavoj Žižek. Ao destacar sua recente exposição midiática, o gosto pelo choque e a presença do paradoxo em sua escrita, LaCapra vai tecendo, com calma e sem grande densidade, seu aproveitamento e crítica da obra de Žižek. O rápido exemplo é quando avalia que o autor de Violência proporciona sempre a "overdose do antídoto" por vezes o "extremo" (p. 154). Sem deter-me em demasia no argumento, LaCapra destaca a busca pelo sublime de Žižek, com sua particular mistura de Lacan e Marx. Enfatiza que a violência é intrínseca à linguagem, especialmente quando pergunta se "os humanos excedem os animais em sua capacidade de violência?” (p. 120). Sua rápida análise de Žižek é concluída com a ponderação de que "para Žižek a essência do humano é o monstruoso, o excesso inumano que marca a incursão do real a possuir uma saída política...” (p. 125)

O texto de LaCapra merece leitura atenta. Tendo sido a coletânea de alguns escritos publicados anteriormente, esse livro tem a marca de um fechamento, não conclusão, de uma carreira de um professor dedicado a pensar Teoria da História e Historiografia. Se esse novo livro dá pouca atenção a alguns temas da década de 1980, como a questão da retórica, tão presente em Rethinking Intellectual History (1983), marca o desaguar de suas reflexôes sobre o trauma e algumas ponderaçóes acerca da importância do sublime para a escrita da História.

Sem a preocupaçáo de detalhamentos excessivos acerca da História, ficção ou filosofia, como fez por vezes Hayden White, LaCapra termina por reafirmar o valor do texto, em sua singularidade e historicidade. Evita cair, desse modo, em consideraçóes, por vezes descomedidas, do caráter inovador de alguns projetos intelectuais que, apenas com o título, propóem a reformulação de um campo. De forma sutil, LaCapra coloca interrogaçóes à identidade do historiador sem excessivo alarde, sem demasiado estrondo; contribui, enfim, para novas reflexóes para a História sem reduzi-la completamente ao seu nível discursivo, não somente nas cátedras de teoria ou história da historiografia. 